\title{
Modification of the low-latitude ionosphere before the 26 December 2004 Indonesian earthquake
}

\author{
I. E. Zakharenkova ${ }^{1}$, A. Krankowski ${ }^{2}$, and I. I. Shagimuratov ${ }^{1}$ \\ ${ }^{1}$ West Department of IZMIRAN, Kaliningrad, Russia \\ ${ }^{2}$ Institute of Geodesy, University of Warmia and Mazury, Olsztyn, Poland
}

Received: 17 July 2006 - Revised: 5 September 2006 - Accepted: 5 September 2006 - Published: 25 September 2006

\begin{abstract}
This paper investigates the features of preearthquake ionospheric anomalies in the total electron content (TEC) data obtained on the basis of regular GPS observations from the IGS network. For the analysis of the ionospheric effects of the 26 December 2004 Indonesian earthquake, global TEC maps were used. The possible influence of the earthquake preparation processes on the main lowlatitude ionosphere peculiarity - the equatorial anomaly - is discussed. Analysis of the TEC maps has shown that modification of the equatorial anomaly occurred a few days before the earthquake. For 2 days prior to the event, a positive effect was observed in the daytime amplification of the equatorial anomaly. Maximal enhancement in the crests reached 20 TECU (50-60\%) relative to the non-disturbed state. In previous days, during the evening and night hours (local time), a specific transformation of the TEC distribution had taken place. This modification took the shape of a doublecrest structure with a trough near the epicenter, though usually in this time the restored normal latitudinal distribution with a maximum near the magnetic equator is observed. It is assumed that anomalous electric field generated in the earthquake preparation zone could cause a near-natural "fountaineffect" phenomenon and might be a possible cause of the observed ionospheric anomaly.
\end{abstract}

\section{Introduction}

The problem of earthquake forecasting is one of the major unsolved tasks of modern geophysics. Due to the last year's events, the development and improvement of forecast methods have taken on added urgency. To this end, intensive research in the field of using seismo-ionospheric effects, together with traditional methods of geophysical forecast-

Correspondence to: I. E. Zakharenkova

(zakharenkova@mail.ru) ing, are being conducted into developing various methods of earthquake forecasting.

Since the Alaska earthquake of 28 March 1964 (M=9.2) research into the seismogenic origin of anomalous effects in different ionosphere parameters have been carried out (Davis and Baker, 1965; Datchenko et al., 1972; Larkina et al., 1983; Gokhberg et al., 1983; Liperovsky et al., 1992).

The launch and evolution of the GPS and GLONASS satellite navigating systems, along with the creation of specialized projects investigating earthquake and volcanic eruption effects in the atmosphere and ionosphere and the vigorous development of worldwide and numerous regional networks of satellite signals receivers, have all led to a new stage of research into ionospheric variations observed before and after strong earthquakes. As a result, over the last 10 years many articles have been published dealing with explanations of the physical mechanisms of lithosphere-ionosphere coupling, along with descriptions of the main features of seismoionospheric phenomena and the first results of a statistical analysis of pre-earthquake effects (Gokhberg et al., 1995; Hayakava, 1999; Hayakava and Molchanov, 2002; Parrot, 1999; Strakhov and Liperovsky, 1999; Pulinets and Boyarchuk, 2004).

There has been great interest in research into the influence of electrical fields caused by seismic processes on the equatorial ionosphere. It is known that the equatorial anomaly reacts sensitively to all changes (of any origin) in electrical fields. The equatorial anomaly (the Appleton anomaly) is a regular phenomenon of the ionosphere, with a deep plasma "trough" near the magnetic equator and two maximal ("crests") displaced $\sim 20^{\circ}-30^{\circ}$ north and south of it.

The equatorial trough in the latitudinal distribution of electron concentration $\mathrm{N}_{e}(\phi)$ occurs in the quiet magnetic conditions in the early morning hours, reaches its greatest development in the afternoon and then gradually disappears. Simultaneously with the trough degradation, the anomaly "crests" (i.e. maximal values of $\mathrm{N}_{e}$ ) move together toward

Published by Copernicus GmbH on behalf of the European Geosciences Union. 

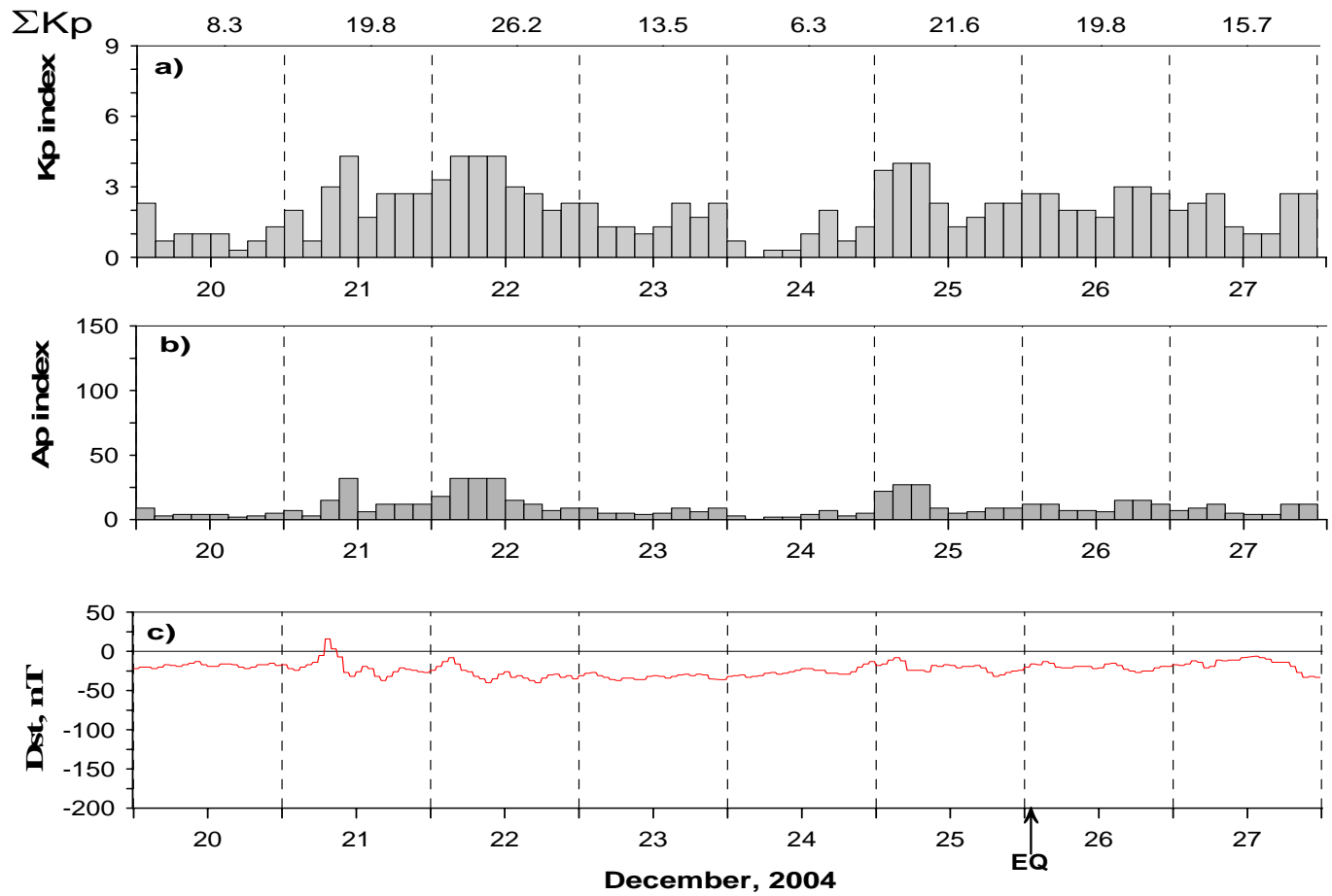

Fig. 1. Geomagnetic conditions on 20-27 December 2004.

the equator and, at night, normal latitudinal distribution with a maximum near the magnetic equator is restored. As a rule, if the anomaly is more strongly expressed, the crests are located further from the magnetic equator (Hanson and Moffett, 1966; Abdu et al., 1981; Fejer et al., 1999; Tsai et al., 2001).

In this paper, the ionosphere variability at low latitudes associated with seismic activity in the Sumatra region on 26 December 2004 has been investigated on the basis of the analysis of the TEC maps created by the GPS-IGS community.

\section{The earthquake description}

The devastating earthquake in question occurred on 26 December 2004. It was the fourth largest earthquake in the world since 1900 and was the largest since the 1964 Alaska earthquake. The earthquake and tsunami caused more casualties than any other in recorded history.

The event magnitude was 9.0. The epicenter position was located off the west coast of northern Sumatra. The geographical coordinates of the epicenter were $3.32^{\circ} \mathrm{N}$ and $95.86^{\circ} \mathrm{E}$. The first shock (M=9.0) occurred at 00:58 UT and the series of powerful aftershocks were registered over the next several days. The zone of aftershocks to the December 26 earthquake was over $1300 \mathrm{~km}$ long.

\section{The geomagnetic conditions}

It is necessary to take into account that the detection of seismo-ionospheric effects is complicated in periods of geomagnetic disturbances, when much stronger variations of the ionospheric parameters "mask" weaker sesmo-ionospheric variations. Figure 1 presents the variations of geomagnetic (Dst) and solar activity indexes (Kp, Ap) in December 2004. The Kp and Ap indexes did not exceed 4, 32, respectively. On the days directly preceding the earthquake, the sum of $\mathrm{Kp}$ varied from the minimal value of 6 up to maximal -26 . The Dst index shows the presence of a weak ionospheric substorm on 21 December. One can see that the geomagnetic situation was rather quiet on all days prior to the earthquake.

\section{Data source}

Current GPS techniques are some of the most efficient means of searching for seismo-ionospheric precursors. In recent years, the ionosonde network has been reduced, while in contrast, the GPS network is being expanded. The GPS permanent network provides regular monitoring of the ionosphere on a global scale with high spatial and temporal resolution of TEC measurements. The data of the ionospheric total electron content (TEC) obtained in the regular GPS observations from the network of IGS stations served as initial data. For the analysis of seismo-ionospheric effects, the global TEC maps in the IONEX format were used. IONEX 

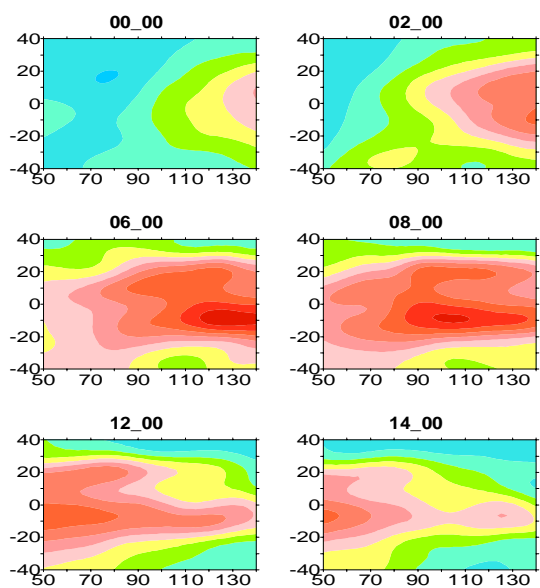

18_00
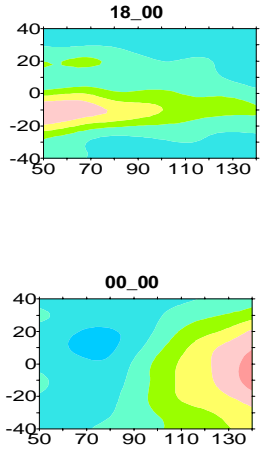

06_00

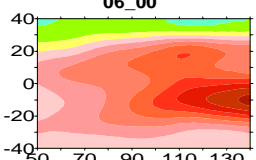

1200
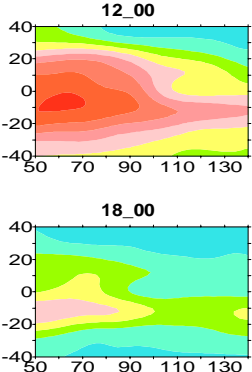

08_00

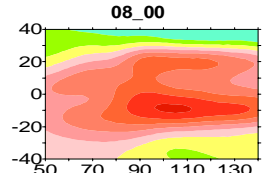

14_00

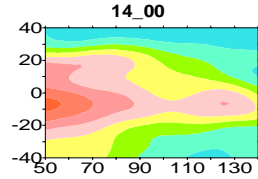

20_00

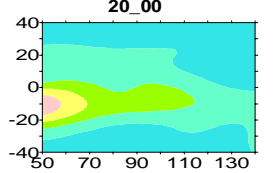

20.12.2004

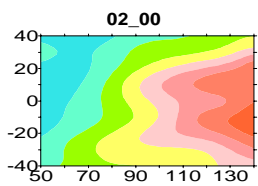

08_00

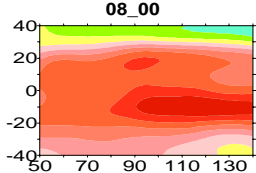

1400

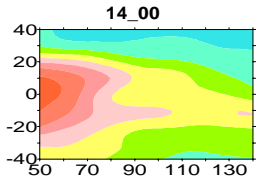

20_00

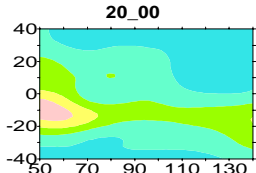

25.12.2004
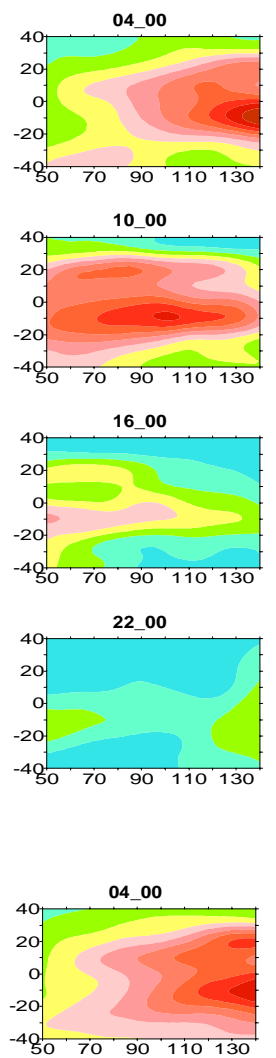

10_00

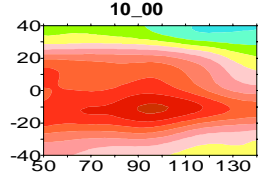

1600

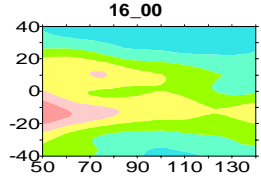

22_00
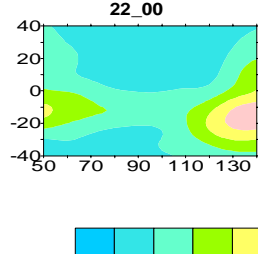

5101520253035404550556065

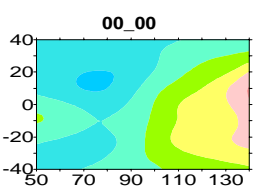

06_00

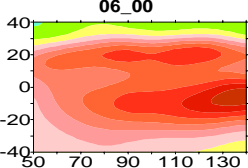

12 00
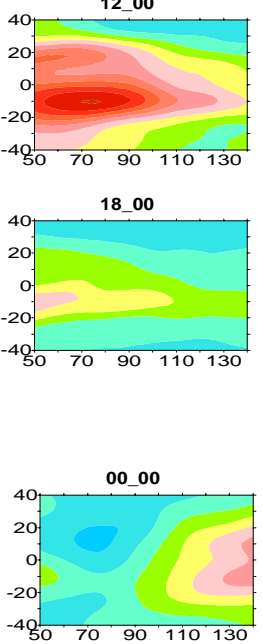

06_00
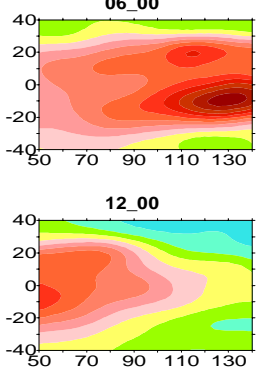

18_00

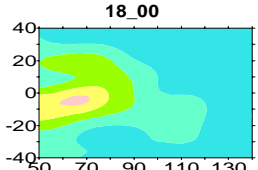

26.12.2004
$20 \_00$
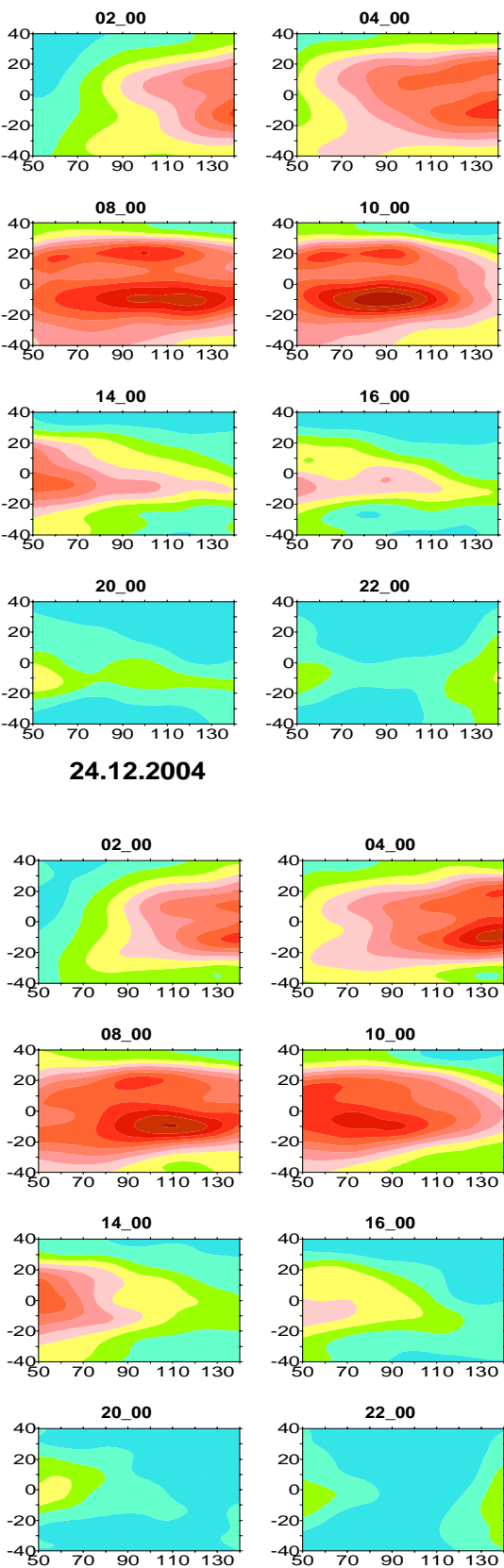

10_00

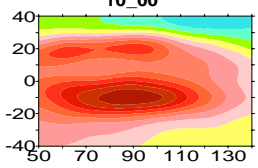

1600

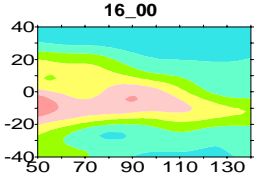

20_00

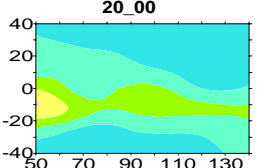

24.12.2004
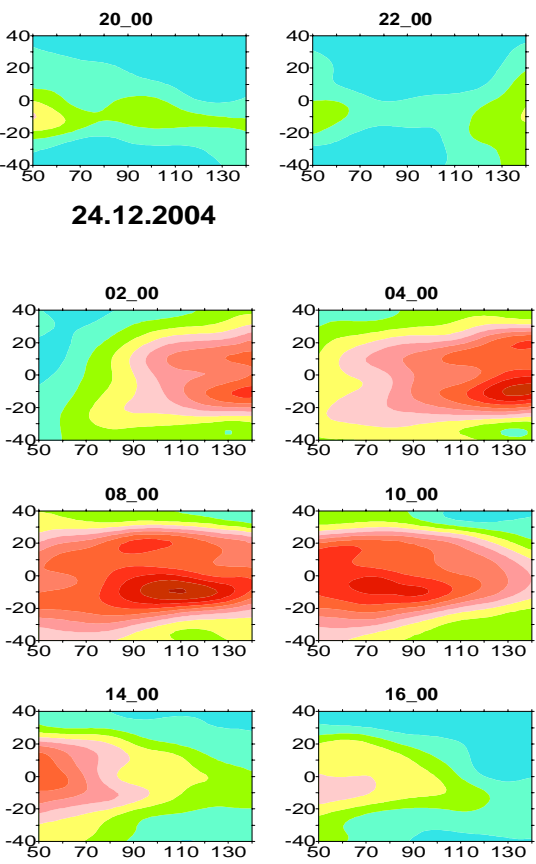

22_00

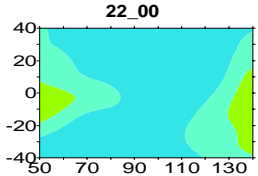

data are accessible at the site: ftp://cddisa.gsfc.nasa.gov/ pub/gps/products/ionex. The global TEC maps are generated routinely by the IGS community with a resolution of $5^{\circ}$ longitude and $2.5^{\circ}$ latitude and a time interval of $2 \mathrm{~h}$. The high correlation between the electron density of the $\mathrm{F} 2$ layer and the TEC confirms that TEC variations can be used to detect seismo-ionospheric anomalies. The accumulated homogeneous material makes it possible to provide a detailed study of the TEC behavior in a particular location and also to add algorithms of seismic anomaly detection in the ionospheric plasma or precursors of seismic activity (Ruzhin et al., 2002; Plotkin, 2003; Pulinets et al., 2005; Zakharenkova et al., 2005, 2006; Krankowski et al., 2006). 

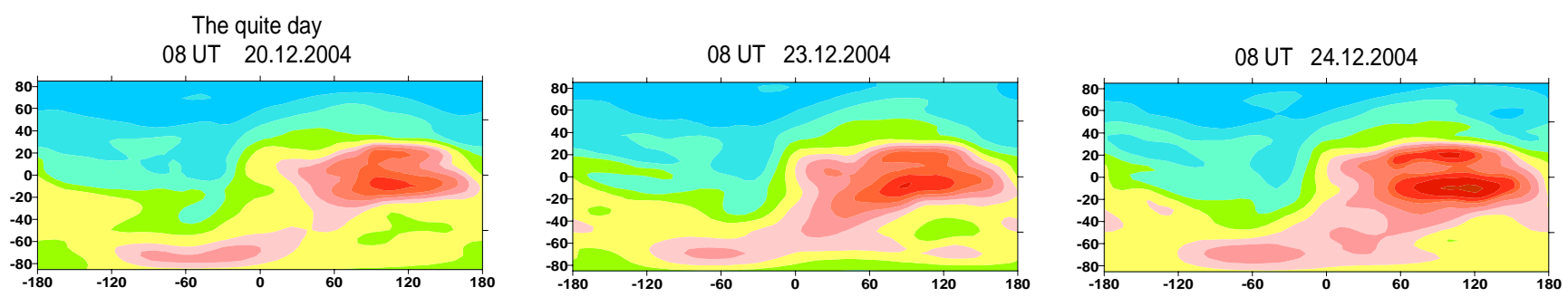

08 UT 25.12 .2004
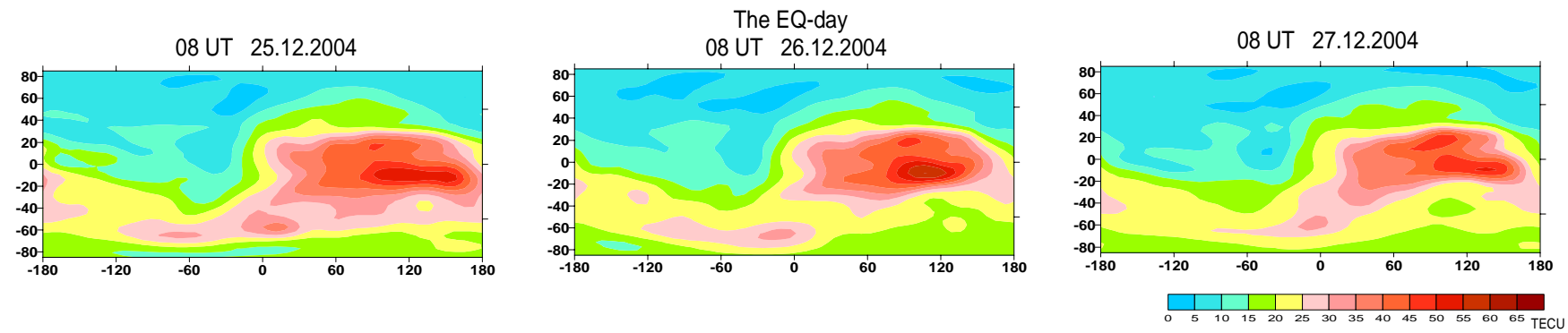

Fig. 3. Global TEC maps for the moment of maximal manifestation of equatorial anomaly for Indonesian region.

\section{Results and discussion}

According to research into seismo-ionospheric responses arising during the low-latitude earthquake preparation stage, it is known that the modification of the equatorial anomaly associated with seismic activity has various display characteristics and is observed from $\sim 3$ days to several hours before the earthquake. These effects are conditionally divided into 3 groups: increasing equatorial anomaly; disappearance of "crests" (the trough filling); disappearance in the form of abnormal change of the trough and "crests" position (Pulinets and Legen'ka, 2002).

It is known that the equatorial anomaly reacts sensitively to any changes in electrical fields of any origin. In the course of the preparatory stage of the equatorial earthquake, there is a penetration of abnormal electrical fields of seismogenic origin into the ionospheric heights, which strengthens or weakens the natural field of equatorial electrojet. It modulates the $E \times B$-drift process and causes the subsequent spatial distribution of electron concentration.

If the zero inclination enters the zone of earthquake preparation, the additional upward plasma rejection arises in the sector above the magnetic equator, causing an increase in the maximal values of electron concentration $\mathrm{N}_{e}$ relative to the "crests" of equatorial anomaly and the trough amplification.

For detection of seismo-ionospheric variations, the global TEC maps in the IONEX format were used. The day of 20 December was chosen as a control day, as the quietest day in the period previous to this earthquake. For this research, a sufficiently large region was chosen: the latitudes ranged from -40 up to 40 degrees, longitude - from 50 up to 140 degrees East. Figure 2 shows the spatial-temporal distribution of TEC (TECU $=10^{16} \mathrm{el} / \mathrm{m}^{2}$ ) for the control day, two days prior to the earthquake and the day of the earthquake. We can see regular variations connected with the dynamics of equatorial anomaly over the course of time. In addition, the amplification of equatorial anomaly with 06:00 up to 12:00 UT is clearly distinct, and corresponds to 13:00-19:00 h of local time (LT=UT+7).

To consider the spatial sizes and amplitudes of the Appleton anomaly, the global TEC maps for the moment of maximal manifestation of the equatorial anomaly for the Indonesian region are given in Fig. 3. It is clear that on the days prior to the earthquake, abnormal TEC behavior was observed. The spatial expansion of the equatorial anomaly, as well as significant enhancement of electron concentration at the equatorial anomaly crests was registered. The maximal increase reached the value of 20 TECU or 50-60\% relative to the non-disturbed level on 24 December.

For more detailed clarification of the equatorial anomaly dynamics, the meridian sections $\left(\lambda=95^{\circ} \mathrm{E}\right)$ of TEC spatial structure were constructed (Fig. 4) and the afternoon hours (13:00-19:00 LT) are included. Geographical latitudes are given on the bottom axis and the top axis shows the magnetic inclination I. The arrow points to the latitude of the epicenter position. The average, calculated for the period from 10 December to 20 December, is denoted by a black line; the green line reflects TEC variation for the control day (20 December). For 25 December (the red line) the increase in TEC values with displacement of maximal significance to the southern direction is observed. For 24 December (the dark blue line), a clear TEC increase is observed and for 10:00 UT (17:00 LT) there is the northern "crest" in the section structure. 
(a)
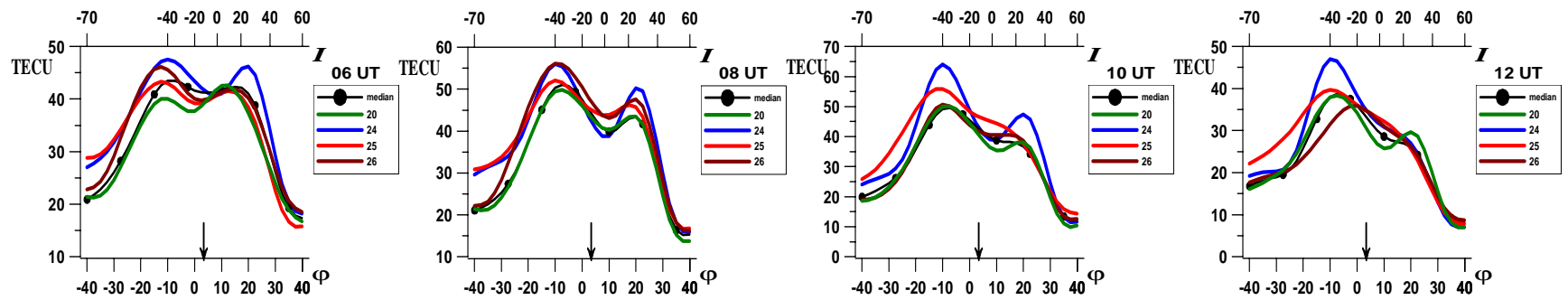

(b)
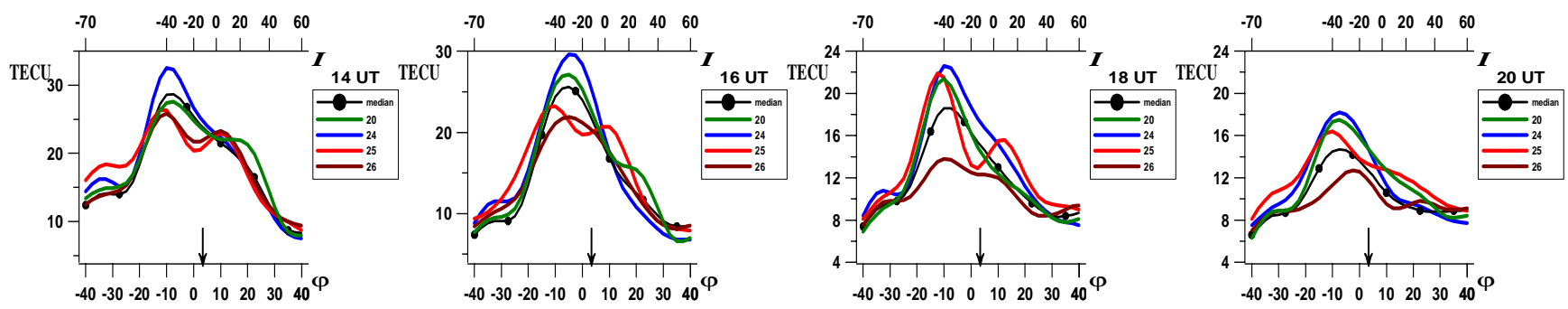

Fig. 4. The meridian sections $\left(\lambda=95^{\circ} \mathrm{E}\right)$ of the TEC spatial structure. On the bottom axis there are geographical latitudes. On the top axis the magnetic inclination I is shown. The arrow points to the latitude of epicentre position.

Similar sections for the appropriate evening and night hours (21:00-03:00 LT) are shown in the second part of Fig. 4. The increase of TEC variation for 24 December (dark blue line) is still marked. On the day prior to the earthquake, the abnormal transformation of the section of TEC values (red line) is fixed and differs essentially from the images of the average line and the control day line. The given variation represents the occurrence of precisely expressed "doublecrests" and a small trough. The trough (minimum) is situated directly above the epicenter area.

For a more visual demonstration of this phenomenon, separate diagrams for the period of 18-26 December were analyzed. Figure 5 presents the meridian sections for the moment of the anomaly maximum manifestation - 18:00 UT corresponds to the 01:00 LT. The comparison of the current day values (color lines) and average meaning (black line) shows that during 18-20 December there are some differences, but the curve shapes are rather similar. However, after 21 December we can see the formation of a doublecrest curve with a trough near the epicenter. It was observed each day prior to the earthquake, except the day of $24 \mathrm{De}-$ cember when a day-long enhancement of electron concentration was registered. One can see the most well-defined effect on 25 December, a few hours prior to the earthquake itself. In addition, this anomaly was observable for several days about 18:00 UT (01:00 LT) and other evening and night hours (21:00-03:00 LT) when it was registered only once, on 25 December.
Recently, Liu et al. (2001) studied the ionospheric variations observed prior to the Chi-Chi earthquake. For this purpose, the Chung-Li ionosonde measurements, as well as the TEC data of the network of 13 GPS receivers were used. The earthquake epicenter position was located in the area of the northern crest of the equatorial anomaly. Thus, the crest displacement caused considerable modification of the diurnal TEC variations over the GPS station. In this case, the results showed that the equatorial anomaly crest moved towards the equator and $\mathrm{f}_{0} \mathrm{~F} 2$ as well as the TEC value significantly decreased 1, 3 and 4 days before the earthquake. It was suggested that the upward electric field near the epicenter and/or the equator-ward neutral wind in the ionosphere stimulated the equator-ward motions and significant TEC decreases in the equatorial anomaly crest.

In the current case, the earthquake epicenter position was located in the area of the anomaly trough between crests. It was assumed that the largest influence would be found in the region nearest to the epicenter close to the magnetic equator. Depueva and Ruzhin (1993) have used the Alouette data to investigate the possible anomalous influence of earthquake preparation processes with the epicenter located near the magnetic equator on the F2 layer latitudinal distribution. It was found that approximately one day before the earthquake, the dependence $\mathrm{f}_{0} \mathrm{~F} 2$ (I) took the shape of a doublecrest curve with a trough near the epicenter. This modification was registered during the evening and night hours (LT), though a similar ionospheric structure (certainly, with greater amplitude) can be observed only in the daytime. 

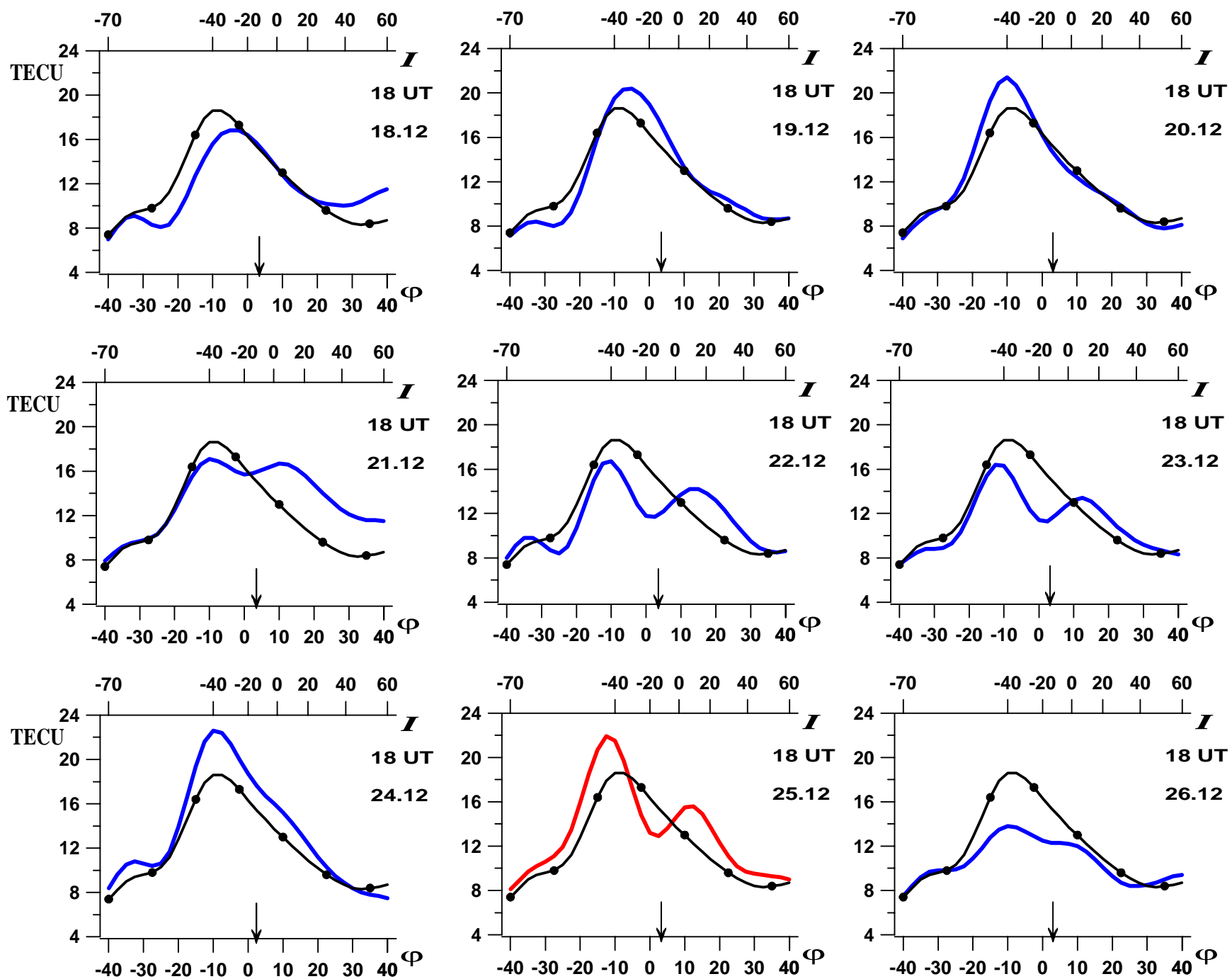

Fig. 5. The meridian sections $\left(\lambda=95^{\circ} \mathrm{E}\right)$ of the TEC spatial structure during 18-26 December (black line - median value calculated for 10-20 December). On the bottom axis there are geographical latitudes. On the top axis the magnetic inclination I is shown. The arrow points to the latitude of epicentre position.

Hence, the modification of the equatorial anomaly associated with Indonesian earthquake had various characteristics and was observed from $\sim 3-4$ days to several hours leading up to the initial shock. At the final stage of the Sumatra earthquake preparation, 2 modifications to the TEC distribution were found. For 2 days prior to the event, a positive effect was observed as a daytime amplification of the equatorial anomaly. Maximal enhancement in the crests reached 20 TECU (50-60\%) relative to the non-disturbed state. Over the previous days, in the evening and night hours (local time), a specific transformation of the TEC distribution had taken place. The structure, an anomaly with two crests and a trough, was observed, though at this time the equatorial anomaly usually disappeared.

\section{Conclusions}

The TEC map analysis has shown that modification of the equatorial anomaly occurred a few days prior to the earthquake. The daytime amplification of the Appleton anomaly was registered during several days prior to the main event. A spatial size increase and maximal values enhancement also took place 2 days before, and the ratio of crests and trough electron concentration was more pronounced than for other days of the discussed period. In addition, according to the ionosphere total electron content data, it was found that in the days prior to the earthquake, the meridian section of TEC spatial structure took the shape of a double-crest curve with a trough near the epicenter. The effect was most pronounced in the evening and night hours (local time) on 25 December, though usually at this time the restored normal latitudinal 
distribution with a maximum near the magnetic equator is observed. It is assumed that an anomalous electrical field generated near the epicenter during the earthquake preparation stage could have caused a near-natural "fountain-effect" phenomenon and might be a possible cause of the observed ionospheric anomaly. Thus, the seismo-ionospheric effect occurred as a specific modification of the equatorial anomaly.

It is believed that further analysis of this problem will lead to improved short-term earthquake prediction abilities in seismo-active regions.

Acknowledgements. The authors are grateful to the IGS community for providing GPS permanent data and to USGS Earthquake Hazards Program for detailed earthquake information.

Edited by: P. F. Biagi

Reviewed by: two referees

\section{References}

Abdu, M. A., Bittencourt, J. A., and Batista, I. S.: Magnetic declination control of the equatorial $\mathrm{F}$ region dynamo electric field development and spread F, J. Geophys. Res., 86, 11 443-11 446, 1981.

Datchenko, E. A., Ulomov, V. I., and Chernysheva, S. P.: The anomalies of the electron concentration of the ionosphere as a possible precursor of the Tashkent earthquake, Doklady Acad. Sci. Uzb. SSR, 12, 30-34, 1972.

Davies, E. and Baker, D. M.: Ionospheric effects observed around the time of the Alaskan earthquake of March 28 1964, J. Geophys.Res., 70(9), 2251-2253, 1965.

Depueva, A. K. and Ruzhin, Y. Y.: The equatorial earthquake preparatory stage as a reason of "fountain-effect" in the ionosphere, Preprint no. 82(1029), M., IZMIRAN, 1993.

Fejer, B. G., Scherliess, L., and Paula, E. R.: Effects of the vertical plasma drift velocity on the generation and evolution of equatorial spread F, J. Geophys. Res., 104, 19 859-19870, 1999.

Gokhberg, M. B., Pilipenko, V. A., and Pokhotelov, O. A.: On the seismic precursors within the ionosphere, Izvestiya Acad. Sci. USSR, Series Physics of the Earth, 10, 17-21, 1983.

Hanson, W. B. and Moffett, R. J.: Ionization transport effects in the equatorial F region, J. Geophys. Res., 71, 5559-5572, 1966.

Hayakava, M. (Ed.): Atmospheric and Ionospheric Electromagnetic Phenomena Associated with Earthquakes, Terra Scientific Publishing Company, Tokyo, Japan, 1999.

Hayakava, M. and Molchanov, O. A. (Eds.): SeismoElectromagnetics: Lithosphere-Atmosphere-Ionosphere Coupling, Terrapub, Tokyo, Japan, 2002.
Krankowski, A., Zakharenkova, I. E., and Shagimuratov, I. I.: Response of the ionosphere to the Baltic Sea earthquake of 21 September 2004, Acta Geophys., 54, 90-101, 2006.

Larkina, V. I., Nalivayko, A. V., Gershenzon, N. I., Gokhberg, M. B., Liperovskiy, V. A., and Shalimov, S. L.: Observation of VLF emission related with seismic activity on the Intercosmos19 satellite, Geomagn. Aeron., 23, 684-687, 1983.

Liperovsky, V. A., Pokhotelov, O. A., and Shalimov, S. L.: Ionospheric precursors of earthquakes, Miesdunarodnaya Nauka, Moscow, 304 pp. (in Russian), 1992.

Liu, J. Y., Chen, Y. I., Chuo, Y. J., and Tsai, H. F.: Variations of ionospheric total electron content during the Chi-Chi earthquake, Geophys. Res. Lett., 28(7), 1383-1386. 2001.

Parrot, M.: Statistical Studies with Satellite Observations of Seismogenic Effects, in:Atmospheric and Ionospheric Electromagnetic Phenomena Associated with Earthquakes, edited by: Hayakava, M., Terra Scientific Publishing Company, Tokyo, Japan, 685-695. 1999.

Plotkin, V. V.: GPS detection of ionospheric perturbation before the 13 February 2001, El Salvador earthquake, Nat. Hazards Earth Syst. Sci., 3, 249-253, 2003, http://www.nat-hazards-earth-syst-sci.net/3/249/2003/.

Pulinets, S. A. and Legen'ka, A. D.: Dynamics of equatorial ionosphere during the preparation of strong earthquakes, Geomag. and Aeron. (in Russian), 42(2), 239-244, 2002.

Pulinets, S. A. and Boyarchuk, K.: Ionospheric Precursors of Earthquakes, Springer, Berlin, Germany, 315 p., 2004.

Pulinets, S. A., Leyva Contreras, A., Bisiacchi-Giraldi, G., and Ciraolo, L.: Total electron content variations in the ionosphere before the Colima, Mexico, earthquake of 21 January 2003, Geofisica International, 44(4), 369-377, 2005.

Ruzhin, Y. Y., Oraevsky, V. N., Shagimuratov, I. I., and Sinelnikov, V. M.: Ionospheric precursors of earthquakes revealed from GPS data and their connection with "sea-land" boundary, Proceed. 16th Wroclaw EMC Symposium, pp. 723-726. 2002.

Strakhov, V. N. and Liperovsky, V. A. (Eds.): Short-Term Forecast of Catastrophic Earthquakes Using Radiophysical Methods (in Russian), Institute of Physics of the Earth, 176 p., Moscow, 1999.

Tsai, H. F., Liu, J. Y., Tsai, W. H., and Liu, C. H.: Seasonal variations of the ionospheric total electron content in Asian equatorial anomaly regions, J. Geophys. Res., 106(A12), 30363-30369, 2001.

Zakharenkova, I. E., Shagimuratov, I. I., and Lagovsky, A. F.: Ionosphere modification during the earthquakes preparation on the basis of satellite system GPS measurements, Radiowaves Propagation: collected articles of XXI All-Russian scientific conference (in Russian), Ioshkar Ola, 25-27 May 2005, 1, 194-198, 2005.

Zakharenkova, I. E., Shagimuratov, I. I., Lagovsky, A. F., and Krankowski, A.: The ionospheric precursors research for the earthquakes of $\mathrm{M} \sim 5.0$ class, Electronic journal "Investigated in Russia", 39, pp. 361-371, http://zhurnal.ape.relarn.ru/articles/ 2006/039.pdf (in Russian), 2006. 